Article type : Research Article

Gestational diabetes mellitus by maternal country of birth and length of residence in immigrant women in Norway

Short running title: Gestational diabetes in immigrant women

Ragnhild B. Strandberg ${ }^{1}$, Marjolein M. Iversen¹, Anne Karen Jenum², Linn Marie Sørbye ${ }^{1,3}$, Eline S. Vik ${ }^{1,4}$, Erica Schytt ${ }^{1,5}$, Vigdis Aasheim ${ }^{1}$, Roy M. Nilsen ${ }^{1}$

${ }^{1}$ Faculty of Health and Social Sciences, Department of Health and Caring Sciences, Western Norway University of Applied Sciences, Bergen, Norway, ${ }^{2}$ General Practice Research Unit (AFE), Department of General Practice, Institute of Health and Society, Faculty of Medicine, University of Oslo, Oslo, Norway, ${ }^{3}$ Norwegian National Advisory Unit on Women's Health, Oslo University Hospital, Oslo, Norway, ${ }^{4}$ Department of Global Public Health and Primary Care, University of Bergen, Bergen, Norway, ${ }^{5}$ Centre for Clinical Research Dalarna, Uppsala University, Falun, Sweden

Correspondence to: Ragnhild B. Strandberg, E-mail: Ragnhild.Bjarkoy.Strandberg@hvl.no

This article has been accepted for publication and undergone full peer review but has not been through the copyediting, typesetting, pagination and proofreading process, which may lead to differences between this version and the Version of Record. Please cite this article as doi: 10.1111/DME.14493

This article is protected by copyright. All rights reserved 
Word count: main text: 3040 , abstract: 222

\section{What's new}

- Immigrant background is associated with gestational diabetes mellitus (GDM), and our study contributes with knowledge on GDM disparities.

- Immigrant women from a number of countries had substantially higher odds of being diagnosed with GDM compared with non-immigrant women.

- The number of women diagnosed with GDM increased with longer length of residence in Norway among immigrant women.

- This study highlights the need of tailored interventions where the differences in GDM prevalence are taken into consideration, in maternity care for the heterogeneous group of immigrant women.

\section{ABSTRACT}

This article is protected by copyright. All rights reserved 
Aims Immigrant women are at higher risk for gestational diabetes mellitus (GDM) than nonimmigrant women. This study described the prevalence of GDM in immigrant women by maternal country of birth and examined the associations between immigrants' length of residence in Norway and GDM.

Methods This Norwegian national population-based study included 192892 pregnancies to immigrant- and 1116954 pregnancies to non-immigrant women giving birth during the period 1990-2013. Associations were reported as odds ratios (ORs) with 95\% confidence intervals (CIs) using logistic regression models, adjusted for year of delivery, maternal age, marital status, health region, parity, education and income.

Results The prevalence and adjusted OR [CI] for GDM were substantially higher in immigrant women from Bangladesh (7.4\%, OR 8.38 [5.41, 12.97]), Sri Lanka (6.3\%, OR 7.60 [6.71, 8.60]), Pakistan (4.3\%, OR 5.47 [4.90, 6.11]), India (4.4\%, OR 5.18 [4.30, 6.24]) and Morocco (4.3\%, OR $4.35[3.63,5.20]$ ) compared to non-immigrants (prevalence 0.8\%). Overall, GDM prevalence increased from $1.3 \%(\mathrm{OR} 1.25[1.14,1.36])$ to $3.3 \%$ (OR $2.55[2.39,2.71])$ after nine years of residence in immigrants compared to non-immigrant women. This association was particularly strong for women from South Asia.

Conclusions GDM prevalence varied substantially between countries of maternal birth and was particularly high in immigrants from Asian countries. GDM appeared to increase with longer length of residence in certain immigrant groups.

\section{Keywords}

Gestational diabetes mellitus, immigrant women, length of residence, population-based study

\section{Introduction}

Gestational Diabetes Mellitus (GDM) is defined as any degree of glucose intolerance with onset, or first recognition during pregnancy $(1,2)$. This definition therefore includes hyperglycaemia that is induced by the pregnancy, and undiagnosed diabetes prior to the pregnancy. The condition is associated with caesarean section, shoulder dystocia, macrosomia, and large for gestational age offspring (3), in addition to later development of type 2 diabetes mellitus in mothers (4). 
Moreover, women who have experienced GDM appear to have a modestly increased risk of miscarriage in the subsequent pregnancy (5).

The prevalence of GDM has increased over the years $(6,7)$, and established risk factors for GDM include higher maternal age, parity and BMI (8). In addition, several studies, including a metaanalysis, showed that immigrant background is a strong independent risk factor for $\operatorname{GDM}(7,9,10)$. However, most previous studies on GDM prevalence are either small or have typically reported GDM data according to large heterogeneous groups, potentially masking a great deal of variation in immigrant subgroups. Therefore, our knowledge of precisely which subgroups are at increased GDM risk is limited, suggesting updated GDM data by maternal country of birth in a large study sample.

Several risk factors for GDM vary with length of residence in the receiving countries. In particular, longer length of residence in receiving countries is associated with increased BMI (11), higher smoking rates (12), and increased risk of preeclampsia (13). Despite this, there is limited knowledge of whether long-term immigrant residents have different risks of GDM than short-term residents. More knowledge on how the association of length of residence with GDM appears in immigrant women from a range of different countries or regions of maternal birth when taking age, parity, and other risk factors into account, may contribute with important knowledge of which immigrant groups might be of specific concern and in need of additional support from maternity caregivers.

The aim of this study was to describe the prevalence of GDM in immigrant women by maternal country- and region of birth compared to Norwegian-born non-immigrants and to examine the associations between the immigrants' length of residence in Norway and GDM.

\section{Participants and methods}

This study used data from the Medical Birth Registry of Norway (MBRN) (14) and Statistics Norway (SSB) (15) for the period 1990-2013. The MBRN contains maternal and offspring information on personal, administrative and health-related aspects for all live- and stillbirths from 16 weeks of gestation (14). The SSB provided the sociodemographic and migration-related data 
for the study sample. The data from MBRN and SSB were merged by using the unique national identity number, which is assigned to each individual who lives or settles in Norway (16).

The total number of pregnancies recorded in the MBRN between the years 1990 and 2013 was 1415 666. Of these, we analysed 1309846 pregnancies to 711677 Norwegian-born women with Norwegian-born parents (non-immigrants) and foreign-born women with foreign-born parents $\left(1^{\text {st }}\right.$ generation immigrant women). We a priori excluded 23855 pregnancies to women with multiple pregnancies, 389 pregnancies to women whose information on maternal country of birth was missing, and another 8625 pregnancies to women with any pre-gestational diabetes. This study focused on GDM in $1^{\text {st }}$ generation immigrant women who had two foreign-born parents.

Therefore, to reduce heterogeneity between groups being compared, we excluded 6362 pregnancies to $2^{\text {nd }}$ generation immigrant women (Norwegian-born with two foreign-born parents), 44019 pregnancies to Norwegian-born with a mixed ethnic background (Norwegian-born with one foreign-born parent), 9194 pregnancies to foreign-born with one Norwegian-born parent, and 13376 pregnancies to foreign-born women with two Norwegian-born parents (Fig. 1). Also, as we lacked information on newly arrived asylum seekers, paperless immigrants and tourists giving birth in Norway, these groups were not included in the study.

Antenatal care for healthy pregnant women in Norway is carried out either by the midwives alone, by the General Practitioners (GP) alone, or in combination with the GP and the midwives, in primary care (17). During the study period, GDM was defined according to WHO (1999) as fasting plasma glucose of $\geq 7.0 \mathrm{mmol} / \mathrm{L}$ or plasma glucose $\geq 7.8 \mathrm{mmol} / \mathrm{L}$ two hours after intake of 75 g glucose (oral glucose tolerance test (OGTT)) (18). From 2009, the National Clinical Guideline for diabetes recommended an OGTT to high-risk women (family history of diabetes, previous GDM, BMI $>27 \mathrm{~kg} / \mathrm{m}^{2}$, age $>38$ years, ethnic minorities from countries outside Europe with high prevalence of diabetes) (19). National Guidelines for Antenatal Care recommend that immigrant pregnant women from Asia and Africa should be routinely screened for GDM (17,2022). We used variables for GDM as defined by MBRN.

Maternal country of birth as registered by SSB was analysed directly as a categorical variable including the 42 countries with the largest number of women, i.e., those countries contributing to most pregnancies during the study period. The remaining countries $(n=158)$ were grouped and analysed as "Other countries". Region of maternal birth was classified according to the seven Global Burden of Disease (GBD) super regions (23): ( i ) Central Europe, Eastern Europe, and 
Central Asia; ( ii ) High-income countries; (iii) Latin America and Caribbean; (iv ) North Africa and Middle East; ( v ) South Asia; ( vi ) Southeast Asia, East Asia, and Oceania; and (vii) SubSaharan Africa.

The registration date according to the National Registry in Norway is the official date of immigration (24). The immigrant women's length of residence in Norway was calculated as the year of childbirth registered in the MBRN minus the year of immigration. The year of immigration was abstracted from the SSB and was the year when the individuals obtained their national identity number registered in the National Registry. Length of residence was analysed as a categorical variable: $<2 ; 2-3 ; 4-5 ; 6-7 ; 8-9$; and $>9$ years (categories were chosen a priori). Nonimmigrant women were coded with a separate code and used as reference category for this variable.

Other variables collected from the MBRN included the year the women gave birth (continuous variable), maternal age at delivery (continuous variable), parity $(0,1,2,3 \geq 4$ previous births), health region in Norway (South/East, West, Middle, North) and marital status at birth (married/cohabiting, not married/cohabiting). Variables collected from the SSB included maternal educational level (no education, primary school, secondary school, university/ college) and maternal income (calculated quartiles for 1990-2013). Maternal age, parity and socioeconomic status have previously been shown to be associated with $\operatorname{GDM}(7,8)$ and were included as adjustment variables in the regression analyses. We also adjusted for health region (South/East, West, Middle and North) in Norway to adjust for a potential geographical difference in GDM prevalence.

\section{Statistical Analyses}

We used logistic regression analysis to estimate the association of maternal country and region of birth with GDM, as well as the associations between length of residence in immigrant women and GDM. In all analyses, the reference group was non-immigrant women and results were reported as odds ratios (ORs) with 95\% confidence intervals (CIs). To account for the dependency among pregnancies by the same mother, we used robust standard errors that allowed for within-mother clustering (25). 
Analyses were performed crude and with adjustments for year of birth, maternal age at birth, parity, health region in Norway, marital status at birth, education and maternal income. To account for non-linear associations, year of birth and maternal age were incorporated in the regression models as polynomial quadratic terms in the regression models. Because GDM increased during the study period and immigrants immigrated on different time points, year of birth was an important adjustment variable for the current analysis.

Due to missing data (see Table 1) on health region, education and maternal income, a multiple imputation strategy by predictive mean matching was applied to produce ten multiply imputed datasets. The imputation model included GDM, length of residence, maternal country of birth, year of birth, maternal age at birth, marital status at birth, health region, parity, education and income. The combination of ORs with $95 \%$ CIs across imputed datasets was calculated using Rubin's combination rules. All analyses were performed using R 3.4.2 for Windows (The R Foundation for Statistical Computing, Vienna, Austria) and Stata IC version 14 (Stata Statistical Software, College Station, TX, USA).

\section{Ethical approval}

This study was approved by the Regional Committee for Medical Research Ethics the $7^{\text {th }}$ of June 2018 , in an overarching project that was approved $10^{\text {th }}$ of September $2014(2014 / 1278 /$ REK South-East).

\section{Results}

Of the 1309846 included pregnancies, 192892 were to immigrant women and 1116954 to nonimmigrant women. In both groups, the women were on average 29 years old and approximately $92 \%$ were married or cohabiting at the time of delivery (Table 1). Immigrant women had a higher parity than the non-immigrant women and they had on average a length of residence in Norway of 6 years $(\mathrm{SD} \pm 6)$ at the time of delivery. Overall, the prevalence of GDM was $2.2 \%$ in pregnancies to the immigrant women and $0.8 \%$ in pregnancies to the non-immigrant women (Table 1).

The prevalence of GDM increased in both immigrant- and non-immigrant women from 1990 to 2013 (Table S1). The strongest increase in GDM prevalence was seen during the period 2009- 
2013 in both groups, but there was a consistently higher prevalence of GDM in immigrant women compared to non-immigrant women throughout the study period.

The prevalence of GDM varied substantially across maternal region- (Table 2) and country of birth (Fig.2). When examining the odds of GDM by the seven GBD super regions, women from the South Asia region (OR 5.51, CI 5.07, 5.98), the Southeast Asia, East Asia and Oceania region (OR 3.00, CI 2.80, 3.21) and the North Africa and Middle East region (OR 2.28, CI 2.11, 2.47) had more than two-fold higher adjusted OR for GDM compared to non-immigrant women.

When comparing the odds of GDM between the 42 maternal countries of birth and non-immigrant women (Fig. 2), the highest ORs for GDM were 8.38 (95\% CI 5.41, 12.97) in immigrant women from Bangladesh, 7.60 (CI 6.71, 8.60) in those from Sri Lanka, 5.47 (CI 4.90, 6.11) in those from Pakistan, 5.18 (CI 4.30, 6.24) in those from India, and 4.35 (CI 3.63, 5.20) in those from Morocco. In addition, immigrant women from Ghana, Algeria, Cuba, Gambia, Nigeria, the Philippines, and China had substantially higher OR for GDM, relative to non-immigrant women. The lowest adjusted OR for GDM was in immigrant women from Lithuania $(0.31,95 \%$ CI $0.19,0.50)$ and Sweden $(0.79,95 \%$ CI 0.64, 0.98) (Fig. 2).

The prevalence of GDM increased substantially with the immigrants' length of residence (Table 2). Compared with non-immigrant women, the adjusted OR of GDM in the immigrant group overall increased from 1.25 (CI 1.14, 1.36) for those who gave birth $<2$ years after arrival to Norway to 2.55 (CI 2.39, 2.71) for those who gave birth $>9$ years after arrival to Norway (Table 2).

When investigating the relationship between the immigrants' length of residence and GDM by the seven GBD super regions, there was a strong increase in GDM prevalence in women from the South Asia region, the Southeast Asia, East Asia and Oceania region and women from the North Africa and Middle East region (Fig. 3). GDM prevalence, unadjusted and adjusted ORs for the association between the immigrant's length of residence and GDM by GBD super region are available in Table $\mathrm{S} 2$.

\section{Discussion}

This article is protected by copyright. All rights reserved 
The prevalence of GDM varied substantially across maternal countries of birth, and immigrant women from Bangladesh, Sri Lanka, Pakistan, India and Morocco had the highest OR of GDM compared to the Norwegian-born non-immigrant women. At regional levels, women from the South Asia region, the Southeast Asia, East Asia and Oceania region, and the North Africa and Middle East region had the highest OR of GDM. Moreover, the OR of GDM appeared to increase with longer length of residence in immigrant women from these regions.

A strength of this national population-based study is that the large sample size (including 1309 846 pregnancies) allowed examining GDM prevalence in pregnancies of immigrant women from a number of maternal countries and regions of birth. Our study also contributed with unique information on the relationship between maternal length of residence and GDM. Using length of residence as an exposure, we were able to distinguish GDM prevalence between long-term immigrant residents from short-term residents, an association that has been lacking in studies of GDM and immigrants (9). However, due to the exclusions of multiple pregnancies and certain immigrant groups (other than $1^{\text {st }}$ generation immigrant women and non-immigrant women), results cannot be generalized to second generation immigrant women, those women who had a mixed parental background, or women with multiple pregnancies (Fig. 1). Another limitation of this study was the amount of missing values in education and income for immigrant women. We used well-established multiple imputation strategies to impute plausible data for these adjustment variables, however, due to the high proportion of missing data, we cannot rule out that skewness in the imputed values for these variables might have occurred.

The overall prevalence of GDM in our study $(0.8 \%$ in Norwegian-born non-immigrants and 2.2\% in immigrant women) is lower than that reported in other GDM studies from Nordic countries $(6,10,26)$. A lower GDM prevalence found in the MBRN compared with that observed in the other studies could reflect a variation in the diagnostic criteria used, characteristics of the study population, or a variation in the coding of GDM. However, GDM could also be subject to some under-reporting especially during the early periods when GDM screening and awareness were low.

The National Clinical Guidelines for Diabetes from 2009 acknowledged the increased risk of type 2 diabetes and GDM in our largest groups of immigrant women, and recommended to perform OGTT in pregnant women from these regions. Awareness about the high risk of diabetes, particularly in South Asians (27), also in our population in Norway, increased gradually from 
about the year 2000. We have reason to believe that the uptake of screening and subsequent OGTT in general differed somewhat between health regions and health personnel groups. We cannot rule out that relatively more South Asians than other groups were offered an OGTT, due to their higher risk. However, other immigrant groups (from Africa and Middle East) have generally higher BMI and obesity rates and would probably have been offered an OGTT based on this well-known risk factor.

Consistent with Urquia et al. (28), we found a higher adjusted odds ratio for GDM in immigrant women from South Asia compared with non-immigrant women. Moreover, our findings of a higher GDM prevalence in immigrant women from Bangladesh, Sri Lanka, Pakistan, India and Morocco agree with findings of a recent population-based study from Denmark (10) and a study among South Asian immigrants in New Jersey, United States (29). In our study, we further showed that immigrant women from a number of additional countries are at substantial increased OR for GDM, including women from Ghana, Algeria, Cuba, Gambia, Nigeria, the Philippines and China (Fig. 2), essentially in line with the screening recommendations by the Norwegian National Guidelines for Antenatal Care (17,20-22).

Our finding that the prevalence of GDM increased with longer length of residence in Norway in immigrant women is consistent with Sørbye et al. (30) in descriptive analysis in an overlapping period (1990-2009) using the same data material as we do. We further showed that GDM increased with length of residence in women from South Asia, Southeast Asia, East Asia and Oceania, and North Africa and Middle East, suggesting that several immigrant groups may be more vulnerable to GDM than others with length of residence in Norway.

A positive relationship between length of residence and GDM was also reported in the recent study by Nielsen et al. from Denmark (10), an association partly explained by maternal age and BMI. Unfortunately, information on pre-pregnancy BMI in MBRN was only available for a limited period from 2008 onwards in our study. With additional missing data from 2008 onwards, adjustment for BMI would yield substantially reduced study sample and thereby also reduced generalizability of findings. Therefore, we did not include BMI as covariate in our study. Results from our study and Nielsen et al.'s study (10) give emphasis on the future need of research examining mechanisms involved in the association between length of residence and GDM in women from different maternal countries of birth. 
Chen et al. (31) examined the influence of acculturation (country of birth, language spoken at home and length of time in the United States) and reported that acculturation was inversely associated with GDM in Asian American women in Los Angeles, and discussed that acculturation could have a protective role (31). Sørbye et al. (30) reported an association between nonspontaneous preterm deliveries and longer length of residence in immigrant women, and the authors discussed the possibility of a higher detection rate of risk conditions among immigrants with longer length of residence due to for instance improved language skills (30). There is a lack of knowledge about positive and negative consequences of acculturation in women in reproductive age with specific focus on GDM. Nevertheless, Commodore-Mensah et al. (32) reported that immigrants residing $\geq 10$ years in the United States were more likely to be obese, have diabetes and being hypertensive compare with people with $<10$ years of residence, and emphasized the need of research examining primary care and health screening in newer immigrants versus longterm immigrants (32). Also, Hawkins et al. (12) reported that immigrant women with longer length of residence were more likely to smoke during pregnancy than those with short length of residence. Moreover, a change into an unhealthier dietary pattern in South Asians after migration to Europe is previously discussed in a review study (33). However, the authors emphasized that dietary change with regard to migration is complex (33), and dietary patterns should be further examined according to length of residence in immigrant women.

Immigrant women from a number of countries, including Bangladesh, Sri Lanka, Pakistan, India, and Morocco, have a substantially higher GDM prevalence compared to Norwegian-born nonimmigrant women. That GDM increased with longer length of residence, particularly among immigrant women from South Asia, underscores the need for further investigation into the risk factors of GDM in immigrant women from these maternal birth regions. Our study highlights the importance of tailored interventions to the heterogeneous group of immigrant women in reproductive age, where the differences in GDM prevalence are taken into consideration.

\section{Funding}

This work was supported by the Western Norway University of Applied Sciences (Norway) 


\section{Conflicts of Interest}

None declared

\section{REFERENCES}

1. Buchanan TA, Xiang A, Kjos SL, et al. What is gestational diabetes? Diabetes Care. 2007;30(Suppl):105S-111S.

2. Galtier F. Definition, epidemiology, risk factors. Diabetes Metab. 2010;36:628-651.

3. Hartling L, Dryden DM, Guthrie A, et al. Diagnostic thresholds for gestational diabetes and their impact on pregnancy outcomes: a systematic review. Diabet Med. 2014;31:319331.

4. Bellamy L, Casas JP, Hingorani AD, et al. Type 2 diabetes mellitus after gestational diabetes: a systematic review and meta-analysis. Lancet. 2009;373:1773-1779.

5. Magnus MC, Wilcox AJ, Morken NH, et al.. Role of maternal age and pregnancy history in risk of miscarriage: prospective register based study. BMJ. 2019;364:1869. 
6. Jeppesen C, Maindal HT, Kristensen JK, et al. National study of the prevalence of gestational diabetes mellitus among Danish women from 2004 to 2012. Scand J Public Health. 2017;45(8):811-817.

7. Anna V, van der Ploeg HP, Cheung NW, et al. Sociodemographic correlates of the increasing trend in prevalence of gestational diabetes mellitus in a large population of women between 1995 and 2005. Diabetes Care. 2008;31:2288-2293.

8. McIntyre HD, Catalano P, Zhang C, et al. Gestational diabetes mellitus. Nat Rev Dis Primers. 2019;5:47.

9. Gagnon AJ, McDermott S, Rigol-Chachamovich J, et al. International migration and gestational diabetes mellitus: a systematic review of the literature and meta-analysis. Paediatr Perinat Epidemiol. 2011;25:575-592.

10. Nielsen KK, Andersen GS, Damm P, et al. Gestational diabetes risk in migrants. A nationwide register-based study of all births in Denmark 2004-2015. J Clin Endocrinol Metab. 2020;105:e692-e703.

11. Menigoz K, Nathan A, Heesch KC, et al. Ethnicity, length of residence, and prospective trends in body mass index in a national sample of Australian adults (2006-2014). Ann Epidemiol. 2018;28:160-168.

12. Hawkins SS, Lamb K, Cole TJ, et al. Influence of moving to the UK on maternal health behaviours: prospective cohort study. BMJ. 2008;336:1052-1055.

13. Naimy Z, Grytten J, Monkerund L, et al. The prevalence of pre-eclampsia in migrant relative to native Norwegian women: a population-based study. BJOG. 2015;122:859-865.

14. Irgens LM. The Medical Birth Registry of Norway. Epidemiological research and surveillance throughout 30 years. Acta Obstet Gynecol Scand. 2000;79:435-439.

15. Statistics Norway. About Statistics Norway. Available online: www.ssb.no/en/ (accessed $24^{\text {th }}$ of June 2019).

16. The Norwegian Tax Administration. Norwegian identification number. Available online: https://www.skatteetaten.no/en/person/foreign/norwegian-identification-number/nationalidentity-number/ (accessed 27 th June 2019).

17. Directorate for Health and Social Affairs. A national Clinical Guideline for Antenatal Care. Edited by Directorate for Health and Social Affairs, 2005.

18. Alberti KG, Zimmet PZ. Definition, diagnosis and classification of diabetes mellitus and its complication. Diab Med. 1998;15:539-553. 
19. Norwegian Health Directorate. National Guideline for Diabetes: Prevention, Diagnosis and Treatment 2009, Oslo.

20. Norsk Gynekologisk Forening. Den Norske Legeforening. Veileder i fødselshjelp 1998 Available online: https://www.legeforeningen.no/foreningsledd/fagmed/norskgynekologisk-forening/veiledere/ (accessed $1^{\text {th }}$ August 2019).

21. Norsk Gynekologisk Forening. Den Norske Legeforening. Veileder i fødselshjelp 2008 Available online: https://www.legeforeningen.no/foreningsledd/fagmed/norskgynekologisk-forening/veiledere/ (accessed 1th August 2019).

22. Helsedirektoratet. Nasjonal faglig retningslinje for svangerskapsomsorgen. Svangerskapsdiabetes. 2017. Available online:

https://www.helsedirektoratet.no/retningslinjer/svangerskapsomsorgen/svangerskapsdiabet es (accessed 26 $6^{\text {th }}$ February 2020).

23. Global Burden of Disease (GBD). GBD Compare. Available online https://vizhub.healthdata.org/gbd-compare/ (accessed 1 th August 2019).

24. Dzamarija MT. Statistics on reasons for immigration 1990-2011, what do we know and how can we best use this information? Statistics Norway: Oslo-Kongsvinger, Norway, 2013.

25. Rabe-Hesketh S, Skrondal A. Multilevel and Longitudinal Modeling Using Stata. 3rd Ed. Stata Press; 2012.

26. Jenum AK, Morkrid K, Sletner L, et al. Impact of ethnicity on gestational diabetes identified with the WHO and the modified International Association of Diabetes and Pregnancy Study Groups criteria: a populatoin-based cohort study. Eur J Endocrinol. 2012;166:317-24.

27. Jenum AK, Diep LM, Holmboe-Ottesen G, Holme IMK, Kumar BN, Birkeland KI. Diabetes susceptibility in ethnic minority groups from Turkey, Vietnam, Sri Lanka and Pakistand compared with Norwegians - the assosiation with adiposity is strongest for ethnic minority women. BMC Public Health. 2012;12:150.

28. Urquia M, Glazier RH, Berger H, Ying I, De Souza L, Ray JG. Gestational diabetes among immigrant women. Epidemiology. 2011;22:879-880.

29. Sanchalika A, Teresa J. Risk of Gestational Diabetes Among South Asian Immigrants Living in New Jersey--a Retrospective Data Review. J Racial Ethn Health Disparities. 2015;2:510-516. 
30. Sorbye IK, Daltveit AK, Sundby J, et al. Preterm subtypes by immigrants' length of residence in Norway: a population-based study. BMC Pregnancy Childbirth. 2014;14:239.

31. Chen L, Shi L, Zhang D, et al. Influence of Acculturation on Risk for Gestational Diabetes Among Asian Women. Prev Chronic Dis. 2019;16:E158.

32. Commodore-Mensah Y, Ukonu N, Obisesan O, et al. Length of residence in the United States is associated with higher prevalence of cardiometabolic isk factors in immigrants: A contemporary analysis of the National Health Interview Survey. J Am Heart Assoc. 2016;5.

33. Holmboe-Ottesen $\mathrm{G}$, Wandel M. Changes in dietary habits after migration and consequences for health: a focus on South Asians in Europe. Food Nutr Res. 2012;56.

Table 1. Sociodemographic, immigrant- and birth-related information on pregnancies in Norway between 1990 and $2013(\mathrm{n}=1309$ 846)

\begin{tabular}{lllll}
\hline & $\begin{array}{l}\text { Pregnancies to non- } \\
\text { immigrant women* }\end{array}$ & \multicolumn{2}{l}{$\begin{array}{l}\text { Pregnancies to } \\
\text { immigrant women }\end{array}$} \\
\hline $\mathrm{N}$ & 1116954 & & 2192892 & \\
Year of birth, $\mathrm{n}(\%)$ & & & & \\
$1990-1993$ & 208105 & $(18.6)$ & 17157 & $(8.9)$ \\
$1994-1998$ & 250311 & $(22.4)$ & 25760 & $(13.4)$ \\
$1999-2003$ & 228184 & $(20.4)$ & 35751 & $(18.5)$
\end{tabular}




\begin{tabular}{|c|c|c|c|c|}
\hline 2004-2008 & 219962 & $(19.7)$ & 47239 & $(24.5)$ \\
\hline 2009-2013 & 210392 & $(18.8)$ & 66985 & $(34.7)$ \\
\hline Maternal age at birth, mean ( \pm SD) & 29.0 & $(5.1)$ & 29.4 & $(5.3)$ \\
\hline \multicolumn{5}{|l|}{ Marital status, n (\%) } \\
\hline Married or cohabitant & 1025052 & $(91.8)$ & 177543 & $(92.0)$ \\
\hline Not married or cohabitant & 91902 & $(8.2)$ & 15349 & (8.0) \\
\hline \multicolumn{5}{|l|}{ Parity, n (\%) } \\
\hline 0 & 459884 & $(41.2)$ & 79055 & $(41.0)$ \\
\hline 1 & 403764 & $(36.1)$ & 63271 & $(32.8)$ \\
\hline 2 & 187040 & $(16.7)$ & 29426 & $(15.3)$ \\
\hline 3 & 48427 & (4.3) & 11917 & $(6.2)$ \\
\hline 4 & 17839 & $(1.6)$ & 9223 & $(4.8)$ \\
\hline \multicolumn{5}{|l|}{ Educational level, n (\%) } \\
\hline No education & 43 & $(<1)$ & 4329 & (3.0) \\
\hline Primary school & 240915 & $(21.6)$ & 45764 & (31.7) \\
\hline Secondary school & 428907 & $(38.5)$ & 39168 & $(27.1)$ \\
\hline University/college & 444869 & (39.9) & 55086 & $(38.2)$ \\
\hline Educational level, missing n (\%) & 2220 & $(0.2)$ & 48545 & $(25.2)$ \\
\hline \multicolumn{5}{|l|}{ Income level, n (\%) } \\
\hline$<25$ percentile & 251088 & $(24.5)$ & 32762 & $(29.2)$ \\
\hline 25-50 percentile & 261566 & $(25.6)$ & 22334 & (19.9) \\
\hline 50-75 percentile & 256578 & $(25.1)$ & 27372 & $(24.4)$ \\
\hline$\geq 75$ percentile & 254058 & $(24.8)$ & 29844 & $(26.6)$ \\
\hline Income level, missing n (\%) & 93664 & (8.4) & 80580 & $(41.8)$ \\
\hline \multicolumn{5}{|l|}{ Health region in Norway n (\%) } \\
\hline South/East & 562873 & $(50.4)$ & 130005 & $(67.5)$ \\
\hline West & 262865 & $(23.5)$ & 34094 & $(17.7)$ \\
\hline Middle & 168260 & $(15.1)$ & 17047 & $(8.8)$ \\
\hline North & 122207 & $(10.9)$ & 11490 & $(6.0)$ \\
\hline Health region in Norway, missing $\mathrm{n}(\%)$ & 749 & $(<1)$ & 256 & $(<1)$ \\
\hline Length of residence (year), mean $( \pm S D)$ & & & 6.0 & (6.0) \\
\hline
\end{tabular}


No

1107556

(99.2)

188670

Yes

9398

(0.8)

4222

Abbreviations: SD, standard deviation

* Non-immigrant women: Norwegian-born women with two Norwegian-born parents

${ }^{\dagger}$ Immigrant women: Foreign-born women with two foreign-born parents.

This article is protected by copyright. All rights reserved 
Table 2. Crude and adjusted odds ratios (ORs) of gestational diabetes mellitus (GDM) in immigrant women by the seven global burden of disease super regions of maternal birth and by length of residence in Norway

\begin{tabular}{|c|c|c|c|c|c|c|c|}
\hline & $\mathrm{N}$ & n GDM & $\%$ & Crude OR & $(95 \% \mathrm{Cl})$ & Adjusted $\mathrm{OR}^{*}$ & $(95 \% \mathrm{Cl})^{*}$ \\
\hline \multicolumn{8}{|l|}{ Maternal birth region } \\
\hline Pregnancies to non-immigrant women ${ }^{\dagger}$ & 1116954 & 9398 & 0.8 & 1.00 & Reference & 1.00 & Reference \\
\hline \multicolumn{8}{|l|}{ Pregnancies to immigrant women } \\
\hline Central Europe, Eastern Europe; and Central Asia & 39530 & 470 & 1.2 & 1.42 & $(1.29,1.56)$ & 0.96 & $(0.87,1.06)$ \\
\hline High income countries & 43804 & 437 & 1.0 & 1.19 & $(1.08,1.31)$ & 0.97 & $(0.88,1.07)$ \\
\hline Latin America and Caribbean & 5096 & 112 & 2.2 & 2.65 & $(2.19,3.20)$ & 1.63 & $(1.35,1.97)$ \\
\hline North Africa and Middle East & 31077 & 793 & 2.6 & 3.09 & $(2.87,3.32)$ & 2.28 & $(2.11,2.47)$ \\
\hline South Asia & 16506 & 730 & 4.4 & 5.45 & $(5.05,5.89)$ & 5.51 & $(5.07,5.98)$ \\
\hline Southeast Asia, East Asia, and Oceania & 32629 & 1080 & 3.3 & 4.03 & $(3.78,4.30)$ & 3.00 & $(2.80,3.21)$ \\
\hline Sub-Saharan Africa & 24250 & 600 & 2.5 & 2.99 & $(2.75,3.25)$ & 1.87 & $(1.71,2.06)$ \\
\hline \multicolumn{8}{|l|}{ Length of residence (years) } \\
\hline Pregnancies to non-immigrant women ${ }^{\dagger}$ & 1116954 & 9398 & 0.8 & 1.00 & Reference & 1.00 & Reference \\
\hline \multicolumn{8}{|l|}{ Pregnancies to immigrant women } \\
\hline$<2$ & 46401 & 609 & 1.3 & 1.57 & $(1.44,1.70)$ & 1.25 & $(1.14,1.36)$ \\
\hline $2-3$ & 39778 & 739 & 1.9 & 2.23 & $(2.07,2.41)$ & 1.66 & $(1.54,1.8)$ \\
\hline $4-5$ & 29086 & 625 & 2.2 & 2.59 & $(2.38,2.81)$ & 1.84 & $(1.69,2.01)$ \\
\hline
\end{tabular}

This article is protected by copyright. All rights reserved 
Per category change

Abbreviations: $\mathrm{Cl}$, confidence intervals; OR, odds ratio

*Adjusted for year of birth, region of birth, maternal age at delivery, marital status, parity, education and income.

${ }^{\dagger}$ Reference group: Norwegian-born non-immigrant women 


\section{Figure Legends}

Figure 1. Flow chart of the exclusion process. The total number of excluded pregnancies to foreign-born women was 22 570. Of these, 77\% (17 398/22 570) pregnancies were to foreign-born women from Sweden, United States, South Korea, Denmark, Great Britain, Germany, Colombia, and Canada, India, and the Netherlands.

Figure 2. Prevalence and adjusted odds ratios (adjusted for year of birth, maternal age at birth, parity, health region in Norway, marital status at birth, education, and income) of gestational diabetes mellitus (GDM) in women by maternal country of birth compared with non-immigrant women

Figure 3. Adjusted odds ratios of gestational diabetes mellitus (GDM) in immigrant women by length of residence in Norway, compared to non-immigrant women (adjusted for year of birth, maternal age at birth, parity, health region in Norway, marital status at birth, education, and income). Stratified analyses by regions of maternal birth according to the seven global burden of disease super regions 


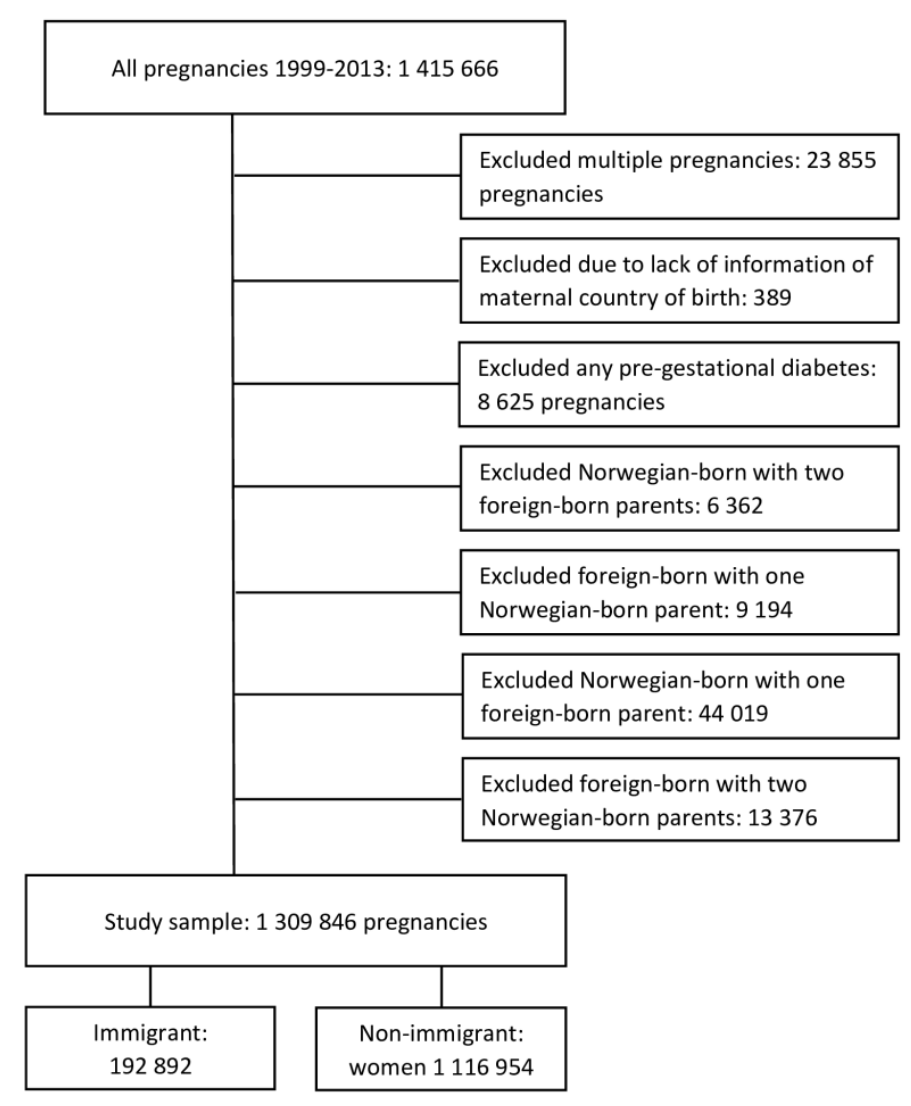

dme_14493_f1.tif

This article is protected by copyright. All rights reserved 


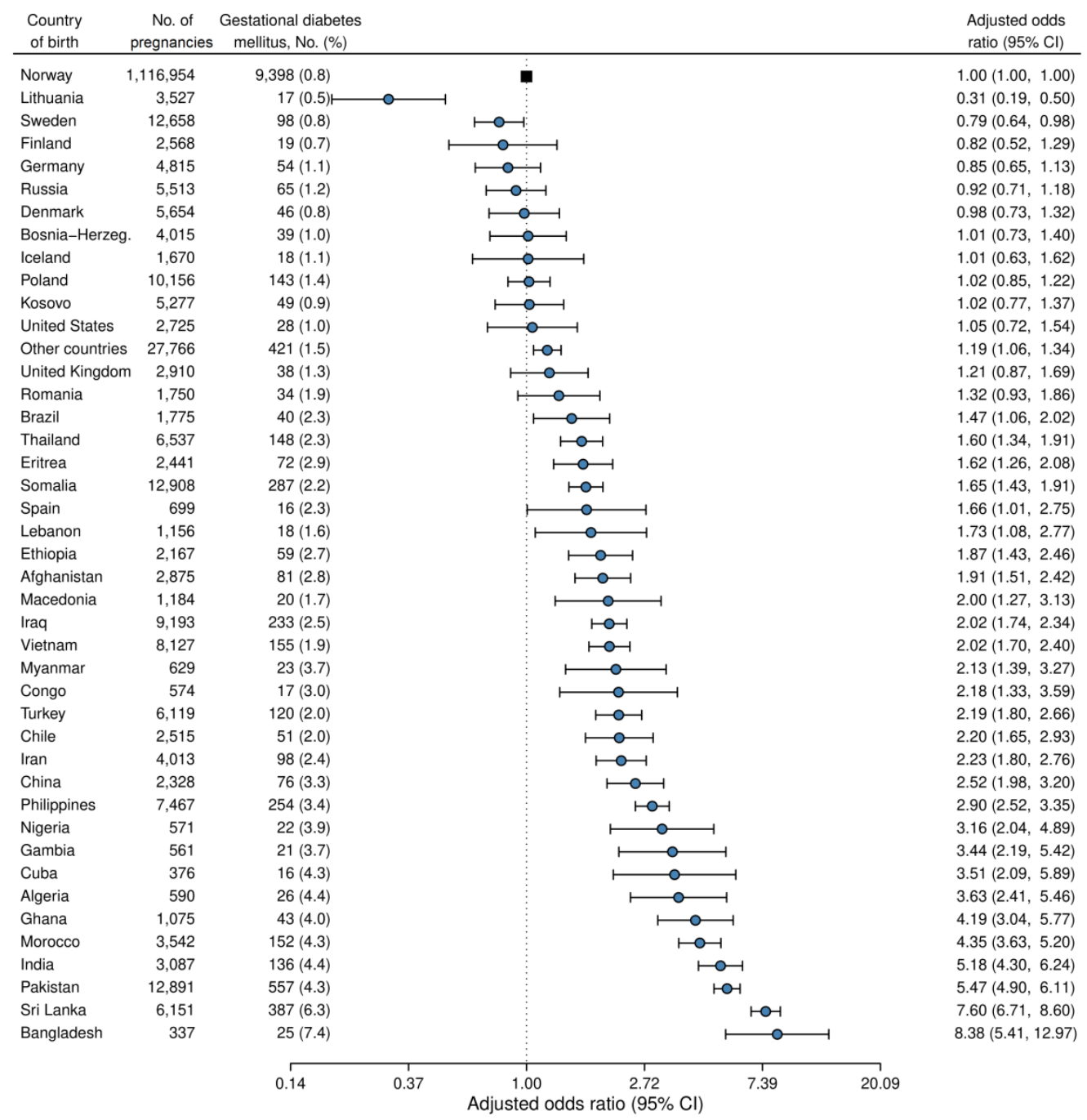

dme_14493_f2.tif 


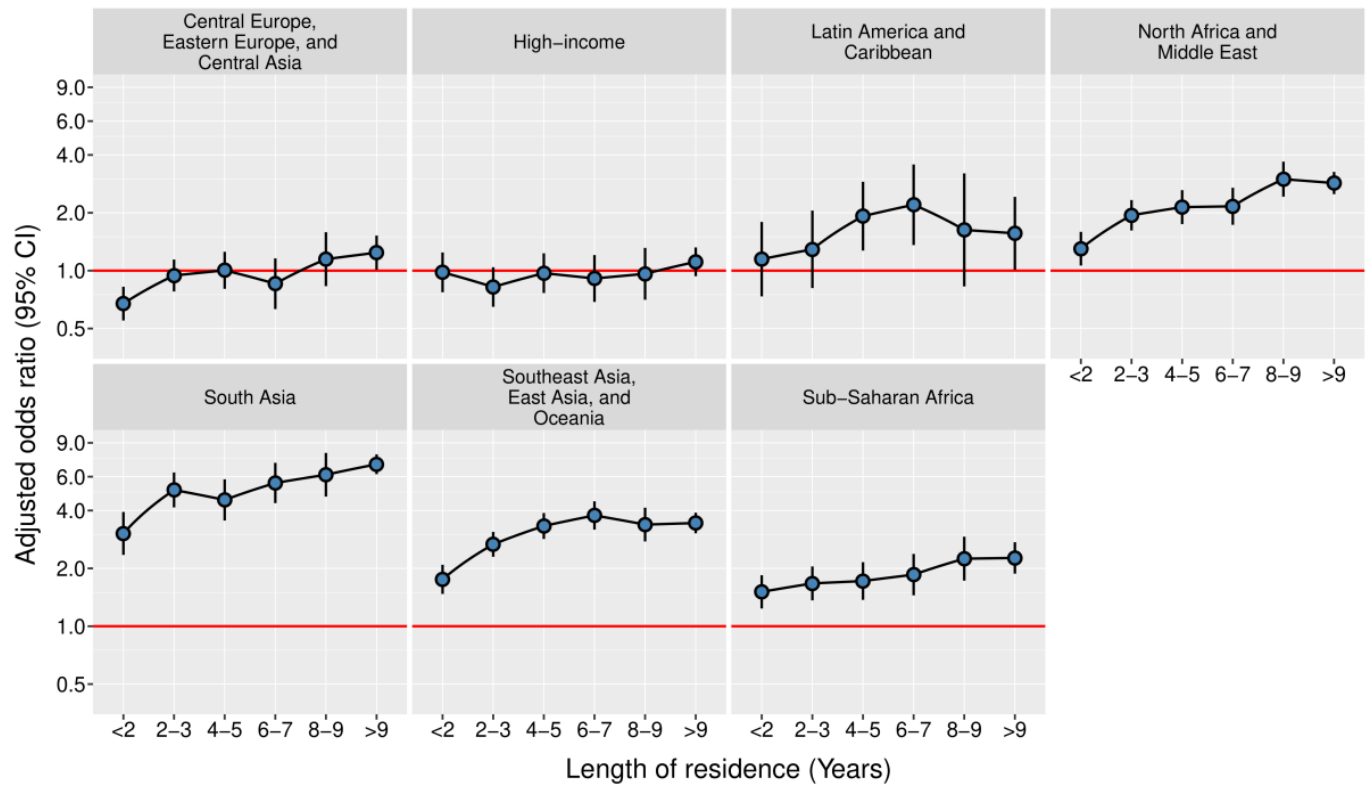

dme_14493_f3.tiff

This article is protected by copyright. All rights reserved 